\title{
Future Perspective of Psychometric Assessment in Screening of Locomotive Drivers for High Speed Train Operation on Indian Railways
}

\author{
Vishnu Kumar ${ }^{1}$
}

\begin{abstract}
:
Train operation at higher speed necessitates attentiveness, alertness and ability to respond promptly with precision and promptness for taking prudent decisions under dynamic situation of train driving. Proficiency and competence of locomotive drivers, their acumen and expertise to formulate strategies for dealing with the varying situations associated with operation of trains involve manifestation of specific cognitive, psychomotor and behavioural abilities, in absence of which their reliability becomes safety critical. Deployment of proficient drivers possessing appropriate attribute and apposite aptitude can be ensured through an efficient psychometric assessment and the process of assessment becomes crucial in minimizing safety critical risk factors and ensuring efficiency and safety in high speed train operation.
\end{abstract}

Keywords: High speed, Cognitive, Psychomotor, Attributes, Skill, Ability, Vigilance, Perception

Attention, Reaction time, Distribution of attention, Personality, Psycho-intervention.

In order to reduce travel time and ensure faster connectivity between major cities, the speed of trains has gradually been increased. Augmentation of speed on some identified routes has been under active consideration by using conventional technology and also by incorporating advanced technology in this field. Introduction of Rajdhani and Shatabdi Express trains that initiated the era of running faster trains necessitated screening of skilled and experienced locomotive drivers, based on certain important psychological attributes of better perception, good observation power, appropriate judgment of speed, acuity for visual differentiation, quick reaction time and application of mental acumen besides physical fitness and ability to withstand monotony and fatigue. In an Endeavour to meet this need the Psycho-Technical Directorate of Research, Designs and Standards Organisation, working under the aegis of the Ministry of Railways, Government of India developed computer aided drivers aptitude test (CADAT) battery indigenously and five tests of this system were chosen to adjudge suitability of locomotive drivers for running trains at speed $\geq 110 \mathrm{kmph}$.

${ }^{1}$ Executive Director/Traffic, Psycho-Technical Directorate, Research Designs and Standards Organisation, Ministry of Railways, Government of India, Manak Nagar, Lucknow-226011, India.

(C) 2015 I V Kumar; licensee IJIP. This is an Open Access Research distributed under the terms of the Creative Commons Attribution License (http://creativecommons.org/licenses/by/2.0), which permits unrestricted use, distribution, and reproduction in any Medium, provided the original work is properly cited. 


\section{Future Perspective of Psychometric Assessment in Screening of Locomotive Drivers for High Speed Train Operation on Indian Railways}

Recent developments and plan to run trains initially at $160 \mathrm{kmph}$ and thereafter at higher speed requires technological and infrastructural improvements and also makes it necessary to deploy efficient and skilled drivers possessing requisite cognitive, psychomotor and behavioural attributes and right aptitude, supported by sharpening of technical skills and abilities for running speedier trains safely and efficiently.

Presently, at the initial stage of recruitment, fresh candidates as well as working employees are selected as Assistant Loco Pilots (ALPs), either directly through Railway Recruitment Boards (RRB) and through departmental selections respectively and this requires mandatory assessment of some basic but critical attributes using indigenously developed aptitude tests. It is essential to qualify in all the five aptitude tests as shown in Table1, either individually in the direct recruitment process or on the basis of aggregate in departmental promotions for being suitable and this forms an integral part of the comprehensive selection process.

Table 1: Assessment of attributes at initial stage of selection

\begin{tabular}{|l|l|}
\hline Criteria & Assessment of Attribute \\
\hline Memory & Memory \\
\hline Following Direction & Ability to follow a set of given instructions \\
\hline Depth Perception & $\begin{array}{l}\text { 3D perception of an object in a visuo-spatial } \\
\text { field }\end{array}$ \\
\hline $\begin{array}{l}\text { Power } \\
\text { Observation }\end{array}$ & Concentration \\
\hline Perceptual Speed & Quick and correct perception of forms \\
\hline
\end{tabular}

As the ALPs grow in the system and acquire adequate field experience of running Mail/Express trains as Loco Pilots (LPs) on various routes with distinct signalling systems and topographical characteristics, they are selected by Railways on the basis of their past safety records, skills and technical capabilities of running faster trains. These locomotive drivers so selected are subjected to screening on indigenously developed CADAT system for assessment of cognitive and psychomotor attributes of reaction time, concentration, judgement of speed, form perception and sustained attention/vigilance and only those who are found suitable as per the established suitability criteria are put on high responsibility job of running trains at speed $\geq 110 \mathrm{kmph}$. Depending upon the need of assessing safety critical cognitive and psychomotor attributes, five tests of CADAT, as shown in Table 2, are administered for screening them at five regional centres. Their performance is assessed on the basis of predetermined suitability criteria on all the five tests combined and those scoring higher than the minimum prescribed cut-off that has been established after several field trials are declared suitable for running high speed trains. 
Table 2: Assessment of attributes for screening experienced Loco Plots for working faster trains

\begin{tabular}{|c|c|c|}
\hline Aptitude test & Assessment & Usefulness \\
\hline $\begin{array}{l}\text { Complex } \\
\text { Reaction } \\
\text { Time }\end{array}$ & $\begin{array}{l}\text { Ability to make prompt response to } \\
\text { various stimuli. }\end{array}$ & $\begin{array}{l}\text { Perception of signal aspects, quick } \\
\text { and appropriate response measured } \\
\text { in milliseconds is crucial for safe } \\
\text { driving. }\end{array}$ \\
\hline $\begin{array}{l}\text { Group } \\
\text { Bourden }\end{array}$ & $\begin{array}{l}\text { Ability to focus and selectively } \\
\text { concentrate on some specific task } \\
\text { excluding the others, especially when } \\
\text { the task is monotonous }\end{array}$ & $\begin{array}{l}\text { Ability to remain focused on main } \\
\text { task of driving without getting } \\
\text { distracted by other insignificant } \\
\text { stimuli. }\end{array}$ \\
\hline $\begin{array}{l}\text { Speed } \\
\text { Perception }\end{array}$ & $\begin{array}{l}\text { Ability to anticipate speed in a visual } \\
\text { field - for this perceptual ability, } \\
\text { attention and focused concentration is } \\
\text { mandatory. }\end{array}$ & $\begin{array}{l}\text { Anticipation of speed aids the } \\
\text { driver to judge situations that may } \\
\text { be critical for safety. }\end{array}$ \\
\hline $\begin{array}{l}\text { Form } \\
\text { Perception }\end{array}$ & $\begin{array}{l}\text { Ability to quick and timely visual } \\
\text { perception of forms in working } \\
\text { environment. }\end{array}$ & $\begin{array}{l}\text { Perceptual speed and discrimination } \\
\text { of forms is crucial for a driver's } \\
\text { job. }\end{array}$ \\
\hline $\begin{array}{l}\text { Visual } \\
\text { Differentiatin } \\
\text { g Attention }\end{array}$ & $\begin{array}{l}\text { Ability to stay alert even in } \\
\text { monotonous situations, where only } \\
\text { once in a while a reaction is required. }\end{array}$ & $\begin{array}{l}\text { Capability of remaining alert over a } \\
\text { sustained period of time is a } \\
\text { prerequisite for driving job. }\end{array}$ \\
\hline
\end{tabular}

Studies and research on the efficacy of psychometric tests in screening the locomotive drivers for selection as high speed locomotive drivers has been scanty and sporadic. However, research conducted by this Directorate (RDSO Report PT-29, 2006) has revealed that the job performance of those locomotive drivers found suitable on CADAT has been better than those declared unsuitable. It has also been found that the suitable locomotive drivers tend to commit less irregularity and are proficient in handling troubles in locomotives/trains more effectively than unsuitable drivers. Further, more than $74 \%$ suitable locomotive drivers were found to be graded as ' $A$ ' which is the highest grading based on their job performance in the field that is independent of psychometric assessment. In another study (RDSO Report PT-36, 2012), performance of locomotive drivers involved in signal passing at danger (SPAD) and accident free drivers were compared on five attributes of CADAT - complex reaction time, form perception, concentration, vigilance, speed perception and anticipation, which suggested that accident free drivers significantly outperformed the accident involved drivers on most of the attributes. These field studies suggested that the CADAT tests are useful in predicting cognitive behaviour and safe performance of locomotive drivers. Moreover, correlational study (RDSO Study Report PT-39, 2014) of the performance of locomotive drivers and field studies conducted 


\section{Future Perspective of Psychometric Assessment in Screening of Locomotive Drivers for High Speed Train Operation on Indian Railways}

to facilitate diligent decisions with respect to assessment of cognitive fitness of skilled and experienced locomotive drivers taking into consideration the impact of age, experience, education and selection process on the performance and to ascertain suitable selection criteria for running trains with sectional speed of 160-200 Kmph and above indicated the need of some modification in the present system of assessment, owing to high cognitive demand involved in driving trains at higher speed of $160-200 \mathrm{Kmph}$ and above. This is obviously so because train driving at such a high speed demands a range of skills and abilities and the basic cognitive functions including perception, attention, memory and the executive functions of reasoning, planning, prioritization, thinking ahead, situational awareness, execution, that determine performance, deteriorate with age. This impact is more pronounced in reaction time, cognitive processing, decision making, multitasking ability, perceptual and psychomotor abilities and the work ability, ultimately leading to errors that affect their ability to drive safely. Ability to withstand the impact of working in different time schedule, particularly night working, also gets reduced, as the critical age for increased intolerance to successive night working has also been found to be around 50 years (Makishita, H., \& Matsunaga, K., 2008; National Institute for Occupational Safety and Health, 2005; Popkin, S. M., Morrow, S. L., Di Domenico, T. E., \& Howarth, H. D., 2008; Verhaegen, P. \& T. A. Salthouse, 1997). However, factors including experience, domain specific expertise, strategies, skills and better job knowledge do have compensatory roles (Taylor, J.L., O'Hara, R., Mumenthaler, M.S., Rosen, A.C., \& Yesavage, J.A., 2005; Yeomans., L., 2010) in reducing these impacts, but need adequate nurturing in the working environment (RDSO Study Report PT-39, 2014).

In this perspective, it becomes essential to standardize the psychometric tests more systematically and explicitly so that they could help in adjudging inherent qualities of locomotive drivers necessary for train operation at higher speed. The present system of aptitude testing with introduction of multiple cut-off as an essential suitability criterion shall do well in screening suitable drivers for running trains at speed upto $160 \mathrm{kmph}$, but it may not be adequate enough to assess other attributes desirable for running trains at still higher speed, which becomes more complex and psychologically demanding. The purpose of this study has been to identify those safety critical attributes for selecting right kind of persons with requisite attributes and right aptitude which could enable them to comprehend technical skills well, respond to dynamic situations spontaneously and develop capability of perfecting proficiency in operation of trains at higher speed without compromising on safety. Rationality of introducing multiple cut-off, while assessing performance on different attributes and augmentation of assessment parameters related to personality, perceptual, cognitive and psychomotor abilities, besides effective implementation of psycho-intervention strategies and sustenance of essential attributes has been found to be of much relevance in ensuring better safety standards. 


\section{Future Perspective of Psychometric Assessment in Screening of Locomotive Drivers for High Speed Train Operation on Indian Railways}

\section{OBJECTIVES OF STUDY}

The objectives of this study have been to

1. Analyse performance of experienced locomotive drivers on different attributes to establish better standards of suitability and introduction of multiple cut-off as an essential suitability criteria.

2. Evaluate present and future requirement of upgrading, modifying and augmenting assessment of attributes for high speed train operation, based on field studies so as to facilitate induction of more proficient drivers for maintaining high standards of safety and efficiency.

3. Assess the need of integrating intervention programmes for well-being of drivers and preservation of attributes essential for safe train operation, enabling them to endure strenuous and fatiguing driving at higher speed.

\section{METHOD}

Data related to performance of 1306 locomotive drivers on CADAT and their suitability was compiled for this study and analysis. It was followed by detailed field studies deputing 42 psychologists and traffic inspectors to footplate on faster trains, including New Delhi-Bhopal Shatabdi Express having speed of $150 \mathrm{kmph}$, running in different environmental and visibility conditions both during day and night to record their observation, and collecting response of 105 drivers and 58 supervisors on specifically designed questionnaire to assess the significance of job related attributes of high speed locomotive drivers. These attributes were rated by 105 drivers, 58 supervisors and 42 psychologist and traffic inspector on a five point "rating scale" ranging from "inevitable" to "not relevant". The information so collected were analysed using statistical software SPSS to adjudge essentiality and criticality of the identified attributes for driving trains at speed in the range of 160 to $200 \mathrm{Kmph}$.

\section{RESULT AND DISCUSSION}

Analyses of the performance of 1306 locomotive drivers on the five selected attributes of CADAT revealed that with present suitability criteria of assessing their aggregate performance $87 \%$ locomotive drivers become suitable, which would decrease to $41 \%$ if the multiple cut-off is introduced as an essential suitability criterion. It would certainly be more stringent, but would help in screening only the most skilled locomotive drivers for high speed train operation. Further analysis indicated that had multiple cut-off been introduced, maximum unsuitability would have been on the attributes of Form Perception followed by Speed Perception, Reaction Time, Sustained Attention and Concentration in that order - all being crucial in high speed train operation. Analysis of unsuitability in different tests that measured different attributes further indicated that out of those found suitable on the basis of present selection criteria, $33.42 \%$ would have been unsuitable based on their performance on either of the five attributes, $20 \%$ would have 


\section{Future Perspective of Psychometric Assessment in Screening of Locomotive Drivers for High Speed Train Operation on Indian Railways}

been unsuitable on different combinations of two attributes and $4 \%$ on different combinations of three attributes.

The essentiality of assessing higher order cognitive, psycho-motor and behavioral attributes for high speed train operation was reviewed on the basis of field studies that depicted rating on various cognitive, psychomotor, personality attributes by locomotive drivers presently working faster trains, their supervisors and real time observation on footplate by the psychologists. This rating indicated that for running trains at higher speed of $200 \mathrm{Kmph}$ and above, assessment of certain attributes would be very much essential. Average rating on various attributes by three separate groups of Loco pilots, Loco inspector/supervisors, and psychologists/ traffic inspectors is shown in Figure 1 to Figure 4. Analysis of their responses on rating scale revealed that among cognitive factors vigilance obtained the highest rating $(86.21 \%)$, followed by memory $(82.21 \%)$, concentration $(81.48 \%$ ), form perception (80.69\%), problem solving (79.02\%), speed perception $(76.72 \%)$ and depth perception $(69.31 \%)$. Among psycho-motor ability reaction time (86.48\%) acquired the highest score, followed by multi-modal reaction time (84.23\%) and distribution of attention (74.45\%). Scores on rating scale on personality dimension further divulged that compliance $(82.07 \%)$ and self-control $(80.25 \%)$ were rated exceedingly as compared to cooperation $(79.32 \%)$ and resilience $(73.11 \%)$.

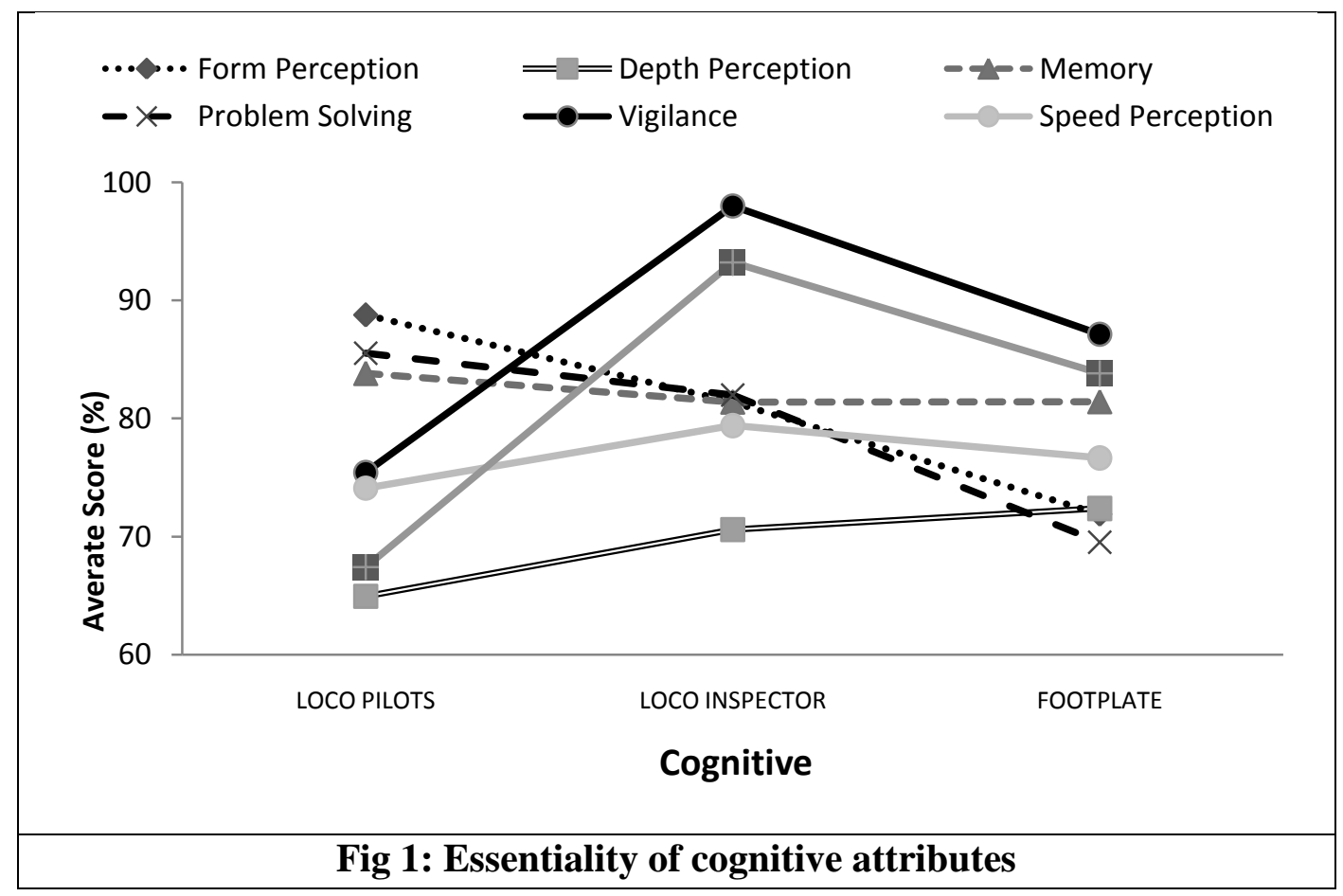


Future Perspective of Psychometric Assessment in Screening of Locomotive Drivers for High Speed Train Operation on Indian Railways
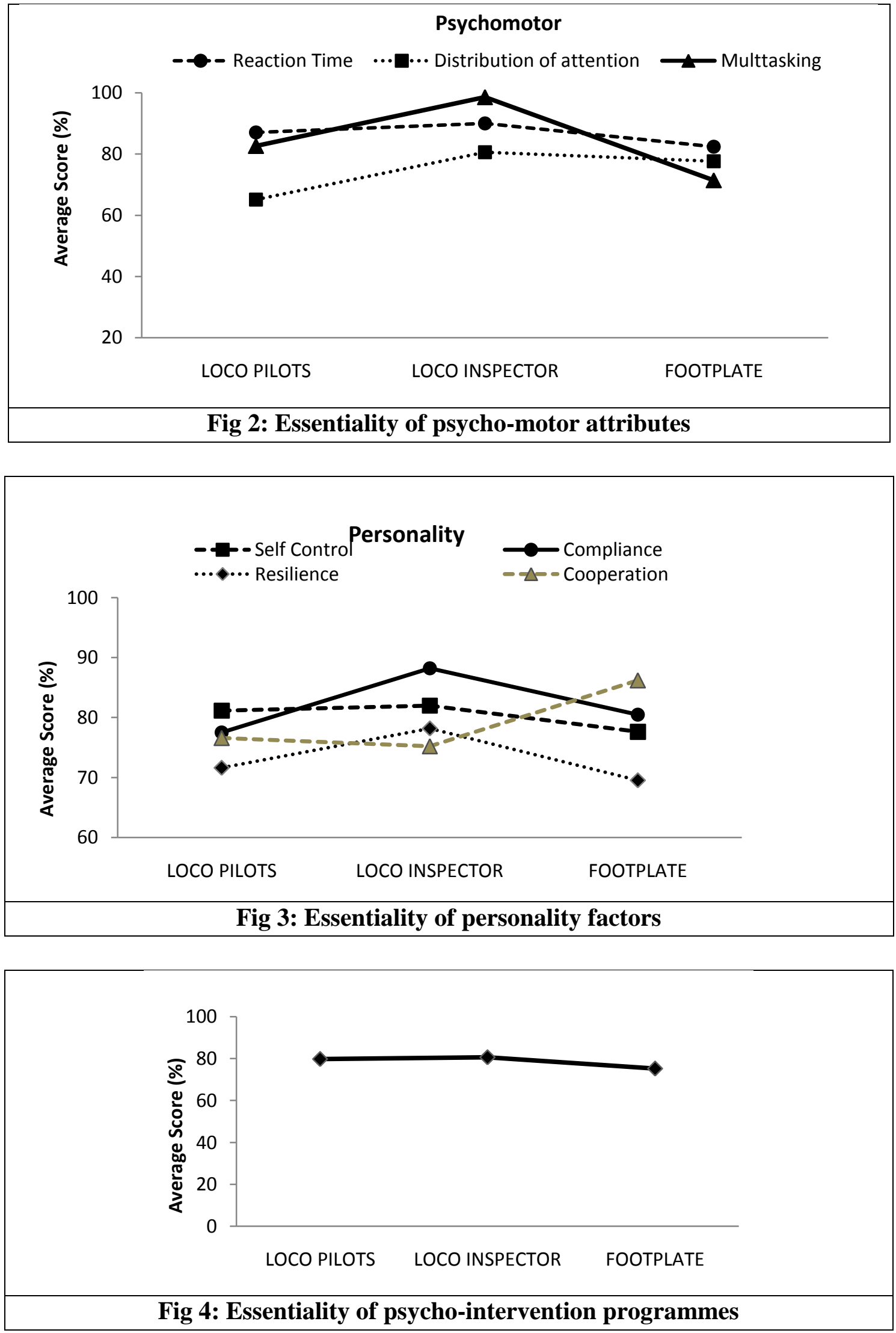


\section{Future Perspective of Psychometric Assessment in Screening of Locomotive Drivers for High Speed Train Operation on Indian Railways}

At higher speeds of train operation human reliability becomes more critical for ensuring safety and since the level of attention and alertness is required to be of the highest order, it becomes essential to ensure that the locomotive drivers possess requisite skills and abilities and are capable of their application by synchronising cognitive, psychomotor, behavioural and personality attributes with technological advancements for maintaining excellent safety standards. To satisfy this expectation it was observed that declaring locomotive drivers suitable on the basis of aggregate performance on five attributes despite their unsuitability in some of the cognitive and psychomotor parameters should not be considered appropriate method of assessment, because proficiency in one cognitive attribute does not compensate deficiency in another attribute. Analysis of the performance of locomotive drivers on different attributes and observation from the field studies indicated that assessment of identified attributes that are presently being used for screening shall be adequate for screening drivers for running trains at $160 \mathrm{Kmph}$ subject to introduction of multiple cut-off as an essential suitability criterion, but the present system of assessing aggregate performance on five attributes will need to undergo progressive change with increase in speed.

\section{Essentiality of attributes and proposed modification in aptitude testing}

The distinctive qualities of locomotive drivers to remain alert, vigilant and able to respond quickly in dynamic situations of train driving at high speed need supplementation by the ability to learn technological knowledge, skills and promptness in applying them while on run, the possibility of which gets decided by good memory and spontaneity. Similarly, attentiveness on sustained basis and distribution of attention enable to perform specific job entrusted to them, which requires handling of cab equipments as and when required and responding to external environmental conditions simultaneously while on run for fairly long period. Prudence of judgement, based on different perceptive abilities, enable them in regulating the speed of trains they are driving. Effective integration of all these attributes eventually determines the overall

performance of locomotive drivers in running high speed trains. In the present study following attributes emerged as essential for driving trains safely at higher speed:

\section{Cognitive:}

- Vigilance,

- speed perception,

- form perception,

- concentration,

- depth perception,

- memory,

- problem solving, 


\section{Psycho-motor:}

- Reaction time,

- multi-modal reaction time,

- distribution of attention.

\section{Personality:}

- Self-control,

- compliance,

- resilience,

- cooperation.

Out of these 14 attributes vigilance, speed perception, form perception, concentration and complex reaction time are presently being assessed on CADAT. Beside these, other attributes which emerged as important for running trains safely at fairly high speed in the range of $200 \mathrm{kmph}$ also need to be assessed progressively along with the five attributes to ensure better safety performance as indicated in Table 3. The above psychometric assessment for screening of locomotive drivers would involve development of psychometric tests, their reliability and validity studies for standardization before they are put in use uniformly. Improving efficacy of the standardized psychometric assessment will be a continuous process.

In addition to psychometric assessment of attributes before their deployment on high speed trains, regular monitoring of the performance of locomotive drivers and reinforcement of organisational support system shall be inevitable for sustenance of aptness among them. Development of safety monitoring system for close observation of the performance of high speed locomotive drivers and timely assessment of the need to upgrade their technical skills, intervention programmes on regular basis for improving and sustaining efficiency shall be indispensible, taking into account certain prominent factors including

- meticulously crafted crew links and rationalization of duty hours

- rest hours and sufficient resting facilities for outstation rest

- taking due care of the effects of consecutive night duties and coping strategies

- reasonably decent working conditions, and

- measures for well-being and work-life balance enabling them to maintain good physical health and mental balance.

Consideration of these factors and concerted efforts to tackle pertinent issues pertaining to sleep deprivation, fatigue and stress shall be of immense help. Various studies including those conducted by this Directorate (RDSO Report 70.3, 1970; PT-08, 1999; PT-19, 2003) have identified various factors that play key roles in performance of locomotive drivers. Effective measures and strategies to mitigate fatigue and stress levels using psycho-assessment, psycho- 


\section{Future Perspective of Psychometric Assessment in Screening of Locomotive Drivers for High Speed Train Operation on Indian Railways}

counselling and meditation exercises as a part of psycho-intervention programmes and motivational strategies, besides periodic medical check-ups would certainly have positive impact on enhancing their skills, acumen and overall performance as high speed train drivers.

The progressive changes in psychometric assessment will have to be supported by some other essential measures, because cognitive and psychomotor attributes and aptitude alone cannot equip the safety employees to perform safely while running high speed trains. These attributes, simply being the strings of mental framework, would essentially need strengthening by means of individual and organizational initiatives, some of them indicated below, that would prove helpful in keeping them in good mental health, which in turn would facilitate cognitive processing, situational awareness and quicker response, enabling them to drive trains at higher speed more safely and efficiently.

- Technical equipments and aids to facilitate their action in response to various dynamic stimuli encountered by them while on run, besides acquaintance with technological advancements,

- Appropriate training on simulators and adequate driving experience in real life situations for development of expertise and automicity,

- Motivational strategies and strengthening of grievance redressal machinery in congenial ambience,

- Counselling programmes at regular intervals for inculcating importance of physical, mental and spiritual health among them for mental and physical fitness.

- Psycho-assessment and inputs of psycho-intervention programmes as a part of regular physical and mental check-ups at defined intervals for their well-being and sustenance of requisite cognitive attributes.

Integration of all these aspects is an absolute necessity as the locomotive drivers need to interact with various auditory and visual stimuli with an ability of quick differentiation and discrimination for processing and organizing appropriate sequence of activities, many of them being simultaneous, before taking prudent decisions as per the safety provisions laid down in stipulated rules and procedures - all requiring fitness of their mental faculty (RDSO Report, PT 81.1, 1981; PT-19, 2003; PT-08, 1999). 
Table 3: Action to be taken for selection of proficient Loco Pilots and sustenance of their abilities

\begin{tabular}{|c|c|c|c|c|c|}
\hline \multicolumn{3}{|c|}{$\begin{array}{l}\text { Assessment of attributes for screening Loco } \\
\text { Pilots for high speed train operation }\end{array}$} & \multicolumn{3}{|c|}{$\begin{array}{l}\text { Enhancement and sustenance of skills, } \\
\text { abilities and expertise }\end{array}$} \\
\hline $\begin{array}{l}\text { Cognitive } \\
\text { abilities }\end{array}$ & $\begin{array}{l}\text { Psychomotor } \\
\text { abilities }\end{array}$ & Personality & $\begin{array}{l}\text { Performance } \\
\text { monitoring } \\
\text { system** }\end{array}$ & $\begin{array}{l}\text { Skill } \\
\text { enhancemen } \\
\text { t } \\
\text { Programmes }\end{array}$ & $\begin{array}{l}\text { Intervention } \\
\text { programmes } \\
* * *\end{array}$ \\
\hline $\begin{array}{l}\text { 1. Vigilance } \\
\text { 2. Speed } \\
\text { perception } \\
\text { 3. Form } \\
\text { perception } \\
\text { 4. Concentration } \\
\text { 5. Depth } \\
\text { Perception* } \\
\text { 6. Memory* } \\
\text { 7. Problem } \\
\text { Solving* }\end{array}$ & $\begin{array}{l}\text { 1. Reaction } \\
\text { Time } \\
\text { 2. Multi } \\
\text { tasking* } \\
\text { 3.Distribution } \\
\text { of } \\
\text { attention* }\end{array}$ & $\begin{array}{l}\text { 1. Self } \\
\text { control* } \\
\text { 2. Comp } \\
\text { liance* } \\
\text { 3. Resili } \\
\text { ence* } \\
\text { 4. Coop } \\
\text { eration* }\end{array}$ & $\begin{array}{l}\text { As an } \\
\text { essential part } \\
\text { of integrated } \\
\text { safety } \\
\text { management } \\
\text { system }\end{array}$ & $\begin{array}{lc}\text { 1. } & \text { Techn } \\
\text { ical skill } \\
\text { 2. } & \text { Traini } \\
\text { ng } & \end{array}$ & $\begin{array}{l}\text { 1. Periodi } \\
\text { c medical } \\
\text { incorporating } \\
\text { the elements } \\
\text { related to } \\
\text { sleep } \\
\text { deprivation, } \\
\text { fatigue and } \\
\text { stress. } \\
\text { 2. Strategi } \\
\text { es for } \\
\text { mitigating } \\
\text { fatigue and } \\
\text { stress. } \\
\text { 3. Psycho } \\
\text {-intervention } \\
\text { 4. Well- } \\
\text { being }\end{array}$ \\
\hline$*$ & \multicolumn{5}{|c|}{ need introduction. } \\
\hline$* *$ & \multicolumn{5}{|c|}{ need reinforcement. } \\
\hline$* * *$ & \multicolumn{5}{|c|}{$\begin{array}{l}\text { need to be taken special care to facilitate synchronisation and professional } \\
\text { adaptability with technological advancements. }\end{array}$} \\
\hline
\end{tabular}

Based on the above and taking into consideration psycho-technical perspective of inducting only those locomotive drivers who are equipped with requisite abilities for safe operation of trains at fairly high speed of $160 \mathrm{Kmph}$ to $200 \mathrm{Kmph}$ and above on Indian Railways, an schematic working model has been depicted below which attempts to illustrate selection of experienced locomotive drivers for high speed train operation in future. This model envisages the findings from the study conducted by this Directorate (Report No. PT-39, 2014) that the locomotive drivers in the age group of 35-50 years who had joined as ALP through direct recruitment process of RRB with ITI/Graduate/Diploma/Degree as their education qualification, 


\section{Future Perspective of Psychometric Assessment in Screening of Locomotive Drivers for High Speed Train Operation on Indian Railways}

and had working experience of 10-15 years performed the best, not only on psychometric assessments, but also in the field. Since educational qualifications of ITI, Diploma and Degree, preferably in electrical and mechanical streams, help in better appreciation of technological advancement for running high speed trains, it may be reasonably appropriate to consider these educational backgrounds as the basic eligibility condition in the recruitment of ALPs through direct recruitment process. Moreover, in this study the impact of biological age, working experience, education and selection process revealed certain characteristic decline in cognitive and psychomotor abilities indicating that relatively younger and educated locomotive drivers with 10 to 15 years of experience selected through direct recruitment process may be more suitable for safe and efficient operation of trains at higher speed.

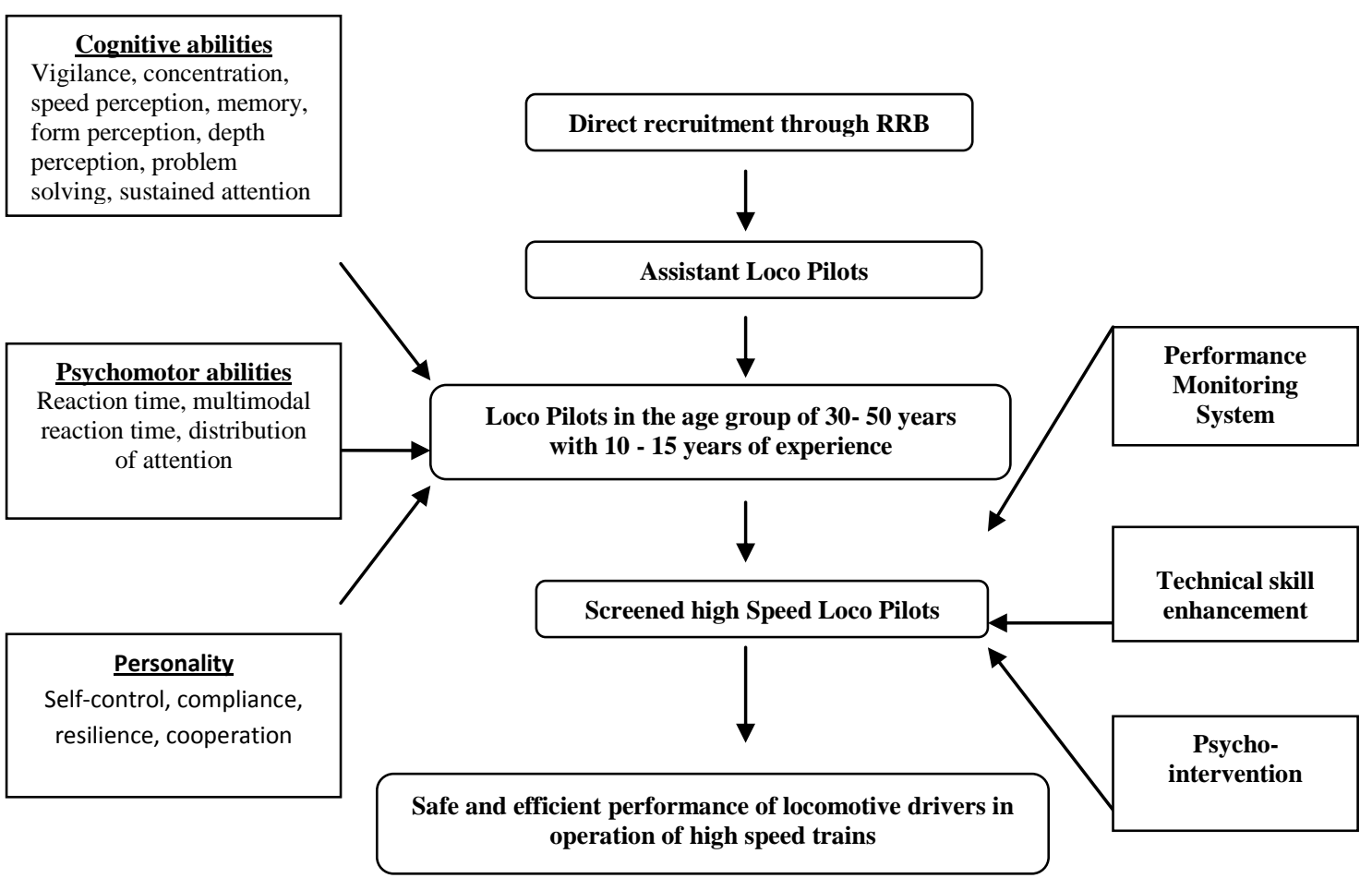

Fig 4: Futuristic model for screening high speed train drivers on Indian Railways.

\section{CONCLUSION}

High speed train operation entails the necessity of selecting the most competent, professionally sound and mentally responsive locomotive drivers for ensuring safety at higher speed. This is so because the job of high speed locomotive driver is different as compared to those responsible for running other passenger carrying trains. Since every psychometric attribute is equally vital and holds equal importance, it is not wise to assess the abilities of drivers and their suitability simply on the basis of aggregate performance. Introduction of multiple cut-off as an essential selection criterion would ensure scientific screening and those found suitable would be of better quality for 


\section{Future Perspective of Psychometric Assessment in Screening of Locomotive Drivers for High Speed Train Operation on Indian Railways}

high speed train operation. Moreover, field studies indicate that increasing speed of trains in the range of $200 \mathrm{Kmph}$ and above in future would require amendments and adjustments in the existing test battery including modification of the existing tests, augmentation of some new ones for assessing desired attributes and introduction of intervention programmes at specified intervals. Assessment of attributes and appropriateness in their application shall be crucial for adjudging suitability of locomotive drivers for safer operation of trains at such a high speed. The primary purpose of psychometric assessment is to evaluate requisite attributes of the locomotive drivers, related to their skills and abilities, which is predictive of their competence to make appropriate judgment and decisions while driving trains at higher speed. Taking into consideration the role of locomotive drivers in train operation it is to be appreciated that they, being the human beings, have own limits and remain susceptible to human fallacies that may have serious repercussion on their performance. The conventional concept that in man-machine system of Railway working the human operators, entrusted to perform specific jobs involving close interactions with machines would be capable of dealing with them, shall adapt to operate any system, even if it is not adequately designed needs to be radically changed. It is of paramount importance that the locomotive drivers likely to be selected as key human operators for operating dynamic and safety critical system should be assessed for their limitations and deficiencies in job specific abilities using standardised and scientific assessment through psychometric testing prior to their deployment on high speed trains. Understanding human behavior and their limitations is essential and the role of assessing attributes is equally essential after the recruitment process in overall interest of an organization.

\section{REFERENCES}

A study on motivational level of NFR drivers, 2003; Psycho-Technical Directorate, $\quad$ RDSO, Study Report No. PT-19, 2003.

A study of disregard of two or more consecutive signals on Indian Railways, 1970; Psycho-Technical Directorate, RDSO, Study Report No. 70.3, 1970.

Analysis of crew alertness and remedial measures. Psycho-Technical Directorate, RDSO, Study Report No. PT-38, 2014.

An analytic study of ALPs involved in SPAD. Psycho-Technical Directorate, RDSO, Study Report No.PT 36, 2012.

Causes and control of stress, 1999; Psycho-Technical Directorate, RDSO, Study Report No. PT-08, 1999.

Contemporary analysis of aptitude testing and future perspective for screening Loco Pilots to run high speed trains. Psycho-Technical Directorate, RDSO, Study Report No. PT-39, 2014.

Effect of age on vigilance capacity of steam locomotive drivers: an experimental study, 1969; Psycho-Technical Directorate, RDSO, Study Report No. 69.5, 1969.

Effect of punishments on the motivation and morale of operating staff - A psychological study, 1981; Psycho-Technical Directorate, RDSO, Study Report No. 81.1, 1981. 
Follow up study on job performance of the drivers tested on high speed driver's test battery, 2006; Psycho-Technical Directorate, RDSO, Study Report No. PT-29, 2006.

Makishita, H., \& Matsunaga, K. (2008). Differences of drivers' reactions times according to age and mental workload. Accident Analysis and Prevention, 40, 567-575.

National institute of occupational safety and health, (2005) Older drivers in the workplace: Crash prevention for employers and workers. Public dissemination, National Institute for occupational Safety and health (NIOSH), 4676, Columbus Ohio, USA.

Popkin, S. M., Morrow, S. L., Di Domenico, T. E., \& Howarth, H. D. (2008). Age is more than just a number: Implications for an aging workforce in the US transportation sector. Applied Ergonomics, 39, 542-549.

Taylor, J.L., O'Hara, R., Mumenthaler, M.S., Rosen, A.C., Yesavage, J.A. (2005). Cognitive Ability, Expertise, and Age Differences in Following Air-Traffic Control Instructions. Psychology \& Aging, 20(1), 117-133.

Verhaegen, P. and T. A. Salthouse (1997). Meta-Analyses of Age-Cognition Relations in Adulthood. Estimates of Linear and Nonlinear Age Effects and Structural Models. Psychological Bulletin, 122(3), 231-249.

Yeomans., L. (2010). An update on the literature on age and employment. Health and Safety Laboratory. 